\title{
PREHISTORIC PEOPLES IN SOUTH AFRICA
}

$\mathrm{D}^{\mathrm{R}}$ R. ROBERT BROOM'Ś recent discoveries in the Transvaal of important evidence bearing upon the origin and descent of man have tended to overshadow another field of anthropological investigation in South Africa which, though more localized in its application, ranks in African ethnology as scarcely of lesser significance for studies of the evolution and distribution of prehistoric racial types. The problem in question arises from the recognition by Dr. A. Galloway* in the skeletal material from the remarkable prehistoric sites of Mapungubwe and Bambadyanalo, recently excavated, of a new race, the BushBoskopoid, associated with and apparently responsible for the mining operations which figure conspicuously among the activities of the prehistoric inhabitants of Rhodesia. The physical characters of the race of miners, their relation to the Bantu-speaking peoples who later came to form the predominant population, and how far the Bush-Boskopoid of Mapungubwe constitutes the type, are discussed in a series of communications made recently to the Rhodesia Scientific Association (Transactions, 37 ; 1939).

In reference to certain human remains found in excavations at various times since 1934, which are recorded in detail by $\mathrm{A}$. E. Phaup, the evidence of the prehistoric skeletal material as a whole from Rhodesia is summarized and discussed by Prof. M. R. Drennan.

By way of preface it is remarked that the remains, both male and female, appear to be those of indigenous natives living under tribal conditions, and using metals. They differ from the present Negroes of South, East and West Africa in that their skulls were longer and narrower than the average, their faces were more prognathous and their brains smaller. They were also shorter. They resemble the "BushBoskop" race of Mapungubwe and Bambadyanalo, and are similar to the more modern "Hottentot" type, seeming intermediate between Bush and Bantu, with some of the characteristics of both. They also show affinities to the Cro-magnon race of Europe. They buried their dead in caves and the ancient workings of prehistoric gold mines. The bodies were probably clothed or covered, and personal ornaments and small utensils were left on or near the body.

The remains were found in different conditions throughout Southern Rhodesia as follows:

Penhalonga. On the Umtali Mission Farm among a group of granite blocks and under the largest was a natural wedge-shaped cavity $50 \mathrm{ft}$. long and $20 \mathrm{ft}$. wide, which had been walled in. The floor was covered with bones and scattered groups of small beads of blue glass and ostrich-shell. Four skulls, three male and one female, were available for examination and were pronounced in a report by Dr. Drennan at the time to be "a good sample of some native group, . . quite comparable to the existing groups of natives".

Makoni District. From a large limestone cave on Romsley extension farm came a human skull and tibia, animal bones, clay pots, grinding stones, a copper bangle and a spear-head. Dr. Drennan pronounced the skull to be female and "typically Bantu", closely resembling two Mashona skulls.

Carolina Claims, Mazoe. An almost complete

* Galloway, A., “The Skeletal Remains from Mapungubwe in "Mapungubwe : Ancient Bantu Civilization on the Limpopo" ". Edited by Leeo Fouché. Cambridge, 1937. female skeleton was collected by the late T. H. Wilson, of the Geological Survey, from the Carolina gold claims, about a mile south of Jumbo siding, in workings in a small hill of banded ironstone. The skeleton was found in reopening one of the old shafts. With it were eight rusty iron rings. Dr. Drennan's report states that the remains are those of a young female of native type aged about twenty years. The skull is comparable with that from Penhalonga, and "definitely negroid in every respect"

Eureka Mine, Sipolilo. Two fossilized fragments of a human femur were found in an ancient working of the gold mine. They show extreme degrees of platymeria and pilastering, features practically never occurring in this degree in Europeans, moderate in Bantu, but a marked feature of Bushman and Hottentot. A fragmentary skeleton of an infant found later, while indeterminate owing to age, is as regards the cranium typically 'negroid', while the mandible is definitely 'Bush-Boskop'.

Inyanga. Fragments of a skull from the Van Niekerk ruins, found lying under a large granite slab, apparently belong to a young female of about fifteen years of age. The measurements are very similar to those of the female from Penhalonga.

In his further review of the skeletal material from Southern Rhodesia as a whole supplementary to the report to which reference is made above, Dr. Drennan states that his interest in the ancient gold miners and other prehistoric inhabitants of Southern Rhodesia was first aroused by the skull from the Gwalo mine presented to the South African Museum by Sir Clarkson Tredgold in 1917. In this skull the features of Bushman, Hottentot and Bantu types are curiously and strikingly blended. Next came the skull from the Planet Mine, Bulawayo, which, while showing certain Bantu characters, is predominantly Bushman, and with reservation might be assigned to the Bush-Boskop group.

The material described by Mr. Phaup, though all legitimately prehistoric Rhodesian, falls into two groups-those with, and those without, a definite association with mining activities. In the mining group fall the Mazoe, the Eureka, and the Van Niekerk specimens; they all belong to the same physical type and are all women or children. The Makoni skull also belongs to the same physical group ; but the group from Penhalonga seem to approximate more to the modern type.

While Dr. Drennan finds a considerable measure of agreement with Mapungubwe, there aro also signifieant differences. The material from Mapungubwe and Bambadyanalo, to which Galloway applies the term Bush-Boskop, is not homogeneous, but includes three or four different elements. In the present series, however, there is no instance of the absolute long-headedness or big-brainedness of the Boskop race, so prevalent at Mapungubwe and Bambadyanalo, nor is their relative long-headedness to be accounted for as a mixture of Bushman and Boskop strains. For this we must look to a pre-negro strain. The pronounced prognathism of the present group emphasizes their negro character; but it is absent at Bambadyanalo.

It is thus impossible to reconcile the two findings at present ; but it may turn out eventually that it is a difference between the exploiters of gold on one hand, 
who show a preponderance of Bush-Boskop character typical of the southern prehistoric peoples, and of the actual miners on the other hand, who show more negroid character inherited from northern pre-negro types such as Elmenteita man.

Upper jaws of a Boskop type attracted the attention of Prof. Raymond Dart in 1938 to the Cornucopia site at Rusape, Umtali, on which Mr. Barnes Pope had been engaged in trenching with the view of discovering the nature of the material there, which had attracted the ancient industrialists responsible for the workings of which evidence had been discovered. The appearance of a Boskop type was unanticipated as all previous skeletons from ancient workings in Rhodesia had been described as Bantu (Keith, 1931) or Bush (Drennan, 1930).

Mr. Barnes Pope, excavating in depressed areas with a luxuriant growth of trees and herbage, which had been disturbed on a grand scale at some past period of time, revealed consistently four layers: (1) the vegetation layer, (2) the gravel or barren layer, (3) the fertile layer, (4) the bed-rock layer.

The bed-rock layer consisted of granite boulders and the disintegrated granite which forms the basis of the area in which the ancient miners worked. The material which attracted them was either the rich brownish-black iron oxide grains, to be used either as a cosmetic or as a source of metallic iron, or alternatively the tin, which though not now found in paying quantities, may originally have been rich. This layer varies from three to forty-five feet.

The fertile layer, from which all objects found underground have come, varies from three inches to several feet in thickness but usually is only twelve inches in height. Here are crude potsherds, skeletal remains, beads, slag, a button of melted tin, etc. Curious arrangements of objects have been discovered. Under a flat stone were thirteen stone phalli. Here there were no bones; but in another place a skull was found accompanied by fifteen phalli. A second skull was found at a depth of fifteen feet, but without accompanying objects.

It may be inferred that two forms of burial were practised : (a) simple and sometimes phalli accompanied burials at the mining face, probably burials of miners; and $(b)$ cylindrical stone monument burials in the 'mine-filling', probably burials of important individuals.

The 'mine-filling' process can be separated into two distinct phases represented by the sterile layer, composed mainly of earth displaced by the miners, and the vegetational stratum-humus, twelve to eighteen inches in thickness, representing the flux of a considerable period of time-certainly several hundreds and it may be even thousands of years. At Zuurberg the humid period represented by the black soil over the former land surface is dated tentatively at 1800 B.C.

This date, which applies to the earliest levels in which occur 'Bushman' burials on the Zuurberg site, is correlated by Wells with the "classical rainfall maximum" of C. E. P. Brooks (1922), dated at a period extending from 1800 B.c. to A.D. 500. The assessment of rate of deposition in South Africa, however, is notoriously difficult and uncertain. The period under investigation was one of aridity and erosion, rather than of precipitation. The rate of deposition of earthy vegetable layers at the present day in South Africa has not been determined; but while it would be rash to jump to the conclusion that the 12-18 in. earthy vegetable layer is referable to the same period as the Zuurberg material, the tentative suggestion of "even thousands of years" may be no exaggeration.

At the same time, cultural evidence from certain sources which have been under review may point to the later limits, for which an approximate dating might be suggested. While weapons and implements of iron are very similar to those collected on ancient ruins of medieval date, or even to those of the modern iron-worker, certain assemblages of beads are comparable to those of the Great Zimbabwe acropolies, that is, of the ninth to tenth centuries of our era, though here again allowance must be made for survival in fashion.

Turning to the skeletal material found on the Cornucopia site, L. H. Wells, in describing the two skulls, stresses their great length and relative narrowness. Thus the more complete of the two measures $201 \mathrm{~mm}$. at its maximum length, while the maximum breadth is only $130 \mathrm{~mm}$., giving a cephalic index of $65 \cdot 0$. The corresponding figures for the second skull are estimated at : maximum length, $190 \mathrm{~mm}$.; maximum parietal breadth, $127 \mathrm{~mm}$.; cephalic index, $66 \cdot 5$ approximately. The cranial capacities, respectively, are $1,425-1,500$ c.c. and $1,300-1,350$ c.c. In both, the bones are thick and massive and slightly mineralized.

The feature, however, which is singled out as especially noteworthy is the remarkable size of the palate and the teeth. In the first skull, the longitudinal and transverse diameters fall just within the maximum recorded for the South African Negro while the height of the palatal vault above the grinding surfaces of the teeth is greater than in any Negro. Moreover, the form is different, the incisors forming an almost straight line between the canines. The palate is thus quadrilateral rather than horseshoeshaped. Except that it is much higher in the vault, this palate agrees with the Boskop type.

Both skulls agree in presenting very few negro features, while of their non-negro features, the majority are proper to the Boskop type.

Yet although these skulls recall the Boskop type, they also diverge widely from it. The significance of these findings becomes apparent on reviewing the skulls previously found in similar circumstances. The number found in Rhodesia is small. Skulls examined by Shrubsall and Keith were classified as of negro type, but probably these conclusions call for revision in the light of further knowledge. Galloway has recognized both Bush and Boskop features from Penhalonga. The Cornucopia find has revealed the association with an ancient occupation site of skeletal remains which are predominantly of non-negro type. They represent a type which there is good reason to believe preceded the Bantu-speaking Negro. Such a strongly marked Boskopoid type is already well known in the southern portions of Africa. The same elongated and low-vaulted skull has been found among the Hottentots and, it has been shown, can arise from the mixture of large-headed Boskop and small-headed Bush types. The most remarkable development of the last few years in South African anthropology has been the demonstration by Galloway (1937) that "a homogeneous Boskop-Bush population physically akin to the postBoskop inhabitants of the coastal caves" was associated with the Iron Age civilization of Mapungubwe. It is concluded that the Cornucopia people, if not identical with the Mapungubwe type, are very similar in most respects. 